\title{
Assessing Educational Needs in Geriatric Care in Ophthalmology: A Single Academic Institution Study
}

Nandini Venkateswaran, MD ${ }^{1}$ Suzanne M. Gillespie, $\mathrm{MD}^{2}$ Rajeev S. Ramchandran, MD, MBA ${ }^{3}$ Matthew D. Gearinger, MD ${ }^{3}$ Holly B. Hindman, MD, MPH 3,4

1 University of Rochester School of Medicine and Dentistry, University of Rochester, Rochester, New York

${ }^{2}$ Division of Geriatrics/Aging, Department of Medicine, University of Rochester Medical Center, Rochester, New York

${ }^{3}$ The Flaum Eye Institute, University of Rochester Medical Center,

Rochester, New York

${ }^{4}$ Center for Visual Science, University of Rochester, Rochester,

New York

J Clin Acad Ophthalmol 2016;8:e30-e38.

\author{
Address for correspondence Holly B. Hindman, MD, MPH, The Flaum \\ Eye Institute, University of Rochester Medical Center, 601 Elmwood \\ Avenue, Box 659, Rochester, NY 14642 \\ (e-mail: Holly_Hindman@URMC.rochester.edu).
}

\begin{abstract}
Keywords

- geriatric education

- continuing medical education

- ophthalmology resident education

Purpose The purpose of this study was to assess the educational needs in geriatric care among practicing and training eye care providers at a single academic institution, the Flaum Eye Institute, at the University of Rochester Medical Center.

Methods Data were collected using a voluntary and anonymous electronic survey that was distributed to 35 training and practicing eye care providers.

Results Of the 35 distributed surveys, 27 (77\%) were returned. Respondents included 6 residents-in-training and 17 practicing providers, based on those who reported demographics. Overall, respondents reported that most of their patients were older than 65 years (mean, $66.4 \%$ ). Notably, $63 \%$ of providers felt they received very little to no prior education in geriatric care. Only $46.4 \%$ reported having a moderate level of interest in geriatric issues. While respondents reported high confidence levels in many geriatric domains, they reported moderate to low confidence levels in several others, including conducting cognitive and functional assessments, assessing and reducing the risk for falls and driving accidents, recognizing depression, and understanding the roles of longterm care and home services, social supports, and geriatric rehabilitation. Differences were also observed in confidence levels between residents-in-training and practicing providers in several geriatric domains.

Conclusion At this single academic institution, current practicing and training ophthalmologists reported having limited prior education in geriatric care and identified many opportunities for geriatric education. While larger-scale studies need to be conducted to produce more generalizable results, this pilot study serves as a guide to augment geriatric education and training of ophthalmologists and improve the quality of eye care for the rapidly growing aging U.S. population.
\end{abstract}

received

July 31,2015

accepted after revision

January 29, 2016
DOI http://dx.doi.org/

10.1055/s-0036-1581112. ISSN 2379-0539.
Copyright $\odot 2016$ by Thieme Medical Publishers, Inc., 333 Seventh Avenue, New York, NY 10001, USA. Tel: +1(212) 584-4662.
License terms

ㄷ) (i) $\ominus$ (\$) 
The proportion of older adults in the United States population is steadily rising due to longer life expectancies and demographics. ${ }^{1-3}$ According to the 2010 census, older adults aged 65 years or older grew by $15.1 \%$ between 2000 and 2010 , and by $12 \%$ in the preceding decade. In 2010 , the older population was 40.3 million, representing $13 \%$ of the total U.S. population, and is projected to double to nearly 88.5 million by $2050 .^{1,2,4}$ Individuals older than 85 years have experienced the fastest growth between 2000 and 2010, with a documented increase of $29.9 \%$, and will number 18.2 million individuals by the year 2050. ${ }^{1,2}$

In ophthalmology, older adults represent a substantial portion of the treated patient population. In $2000,12.8 \%$ of the total number of medical office visits made by patients older than 65 was to their ophthalmologists, and this ranked second to visits made to their internists, which comprised $26 \%$ of total office visits. ${ }^{3}$ In $2010,54 \%$ of the total patient visits made to ophthalmologists were by individuals 65 years of age and older. ${ }^{5}$ Vision loss is a leading cause of disability for individuals older than 60 years, with conditions such as refractive error, cataracts, glaucoma, and macular degeneration contributing most to visual disability and low vision in this population. ${ }^{4,6-9}$ Potentially blinding conditions such as giant cell arteritis, nonarteritic anterior ischemic optic neuropathy, and cerebral strokes are also seen primarily in older adults. $^{8}$ According to 2010 data from the National Eye Institute, $25.66 \%$ of individuals 80 years and older suffered from low vision as compared with only $0.59 \%$ of patients between the ages of 55 and 59 years. ${ }^{10}$ Although persons aged 80 years and older comprise only $7.7 \%$ of the U.S. population, a study by Congdon et al in 2000 showed that they accounted for $69 \%$ of observed cases of blindness in the United States. ${ }^{11}$ Poor vision in the elderly population is associated with decreased overall health and function, impairment of activities of daily living and mobility, social isolation, increased risk of falls and hospitalizations, greater risks for illnesses such as dementia, depression, and anxiety, and higher mortality. ${ }^{4,6-9}$

It is evident that the aging population is significantly affected by ocular pathology and low vision. ${ }^{12}$ Older patients present with complex needs, and it is critical for eye care providers to be competent in specific geriatric care issues that impact vision care and rehabilitation in older adults. Given the projected dramatic increase in the older adult population in the United States, training and education in geriatric care will allow practicing eye care providers to tailor their medical approaches, effectively address unique issues faced by their older patients, and provide focused, highquality medical care for this vulnerable population. ${ }^{3,4,6,7}$ However, studies have demonstrated that gaps are present in the existing knowledge base in geriatric ophthalmology and identify a need to increase geriatric expertise in ophthalmology. ${ }^{4,6}$

We hypothesize that lack of training in the care of older adults is associated with lower perceived competency and confidence levels in recognizing and addressing key areas of older adult care among eye care providers. As such, the goal of this study was to understand perceived confidence and comfort of training and practicing eye care providers at a single academic center in attending to key areas of older adult care. We know of no prior studies in the literature evaluating self-reported competencies in geriatric care issues among eye care providers. Self-perceived competencies were assessed using an electronic survey. The obtained data were used to identify opportunities for geriatric education in ophthalmology to help eye care providers grow more aware to the needs of their older adult patients.

\section{Methods}

\section{Survey Participants}

Approval was sought and granted from the University of Rochester's Institutional Review Board for this study. Exemption for informed consent was granted. A voluntary and anonymous electronic survey was distributed to 35 eye care providers (attending eye care providers $[n=23]$ and residents-in-training [ $n=12]$ ) at the Flaum Eye Institute at the University of Rochester Medical Center. Answers from all completed surveys were stored in a secure Redcap electronic database and subsequently analyzed.

\section{Development of the Survey}

The survey (see supplementary Appendix 1 in the online version of this article) was developed by the authors of the study. A survey developed by the Reynold's foundation was adopted and competencies related to low-vision care outlined in the International Council of Ophthalmology's (ICO) Residency Curriculum were reviewed and incorporated into the survey. ${ }^{13}$ Some questions were also adapted from a previously published study by Friedman et al. ${ }^{14}$ The survey consisted of three sections: (1) background and interest in geriatrics, (2) clinical practice and teaching related to the care of older patients, and (3) participant demographic information. In the first section, participants were asked to provide information regarding their interest and prior training in geriatric care, as well as report the demographics of their older patient populations. In the second section, participants were asked to rate their levels of confidence in personally performing and applying 22 different clinical assessments in the older population and in providing collaborative care. Physicians rated their confidence levels on a 5 -point Likert psychometric scale, ranging from 1 (low) to 5 (high). In the final section, participants were asked to provide their level of training, area of subspecialty, and additional demographic information, including age, gender, and race.

When analyzing results from the third section of the survey, data were stratified according to levels of confidence. Similar Likert responses were reported in summation as percentages to reflect global confidence levels for all clinical practices. Low confidence included options 1 and 2 and high confidence included options 4 and 5. Moderate confidence included only option 3 and was grouped separately. These results were first analyzed in aggregate and subsequently analyzed to compare confidence levels between residents-intraining and practicing providers. 


\section{Results}

Of the 35 distributed surveys, 27 were returned (77\%). The total number of respondents per question varied and questions not answered on an individual respondent's survey were excluded from the final data analysis. The number of surveys from which the data are extracted is denoted for all reported results.

\section{Survey Respondents' Demographics}

Survey respondents' demographic information is described in -Table 1.

Patient Demographics and Prior Training in Geriatrics Respondents reported that a mean of $53.1 \%$ of their treated patients over the past 2 years were between the ages of 65 and 79 years, while a mean of $13.3 \%$ of their patients were older than 80 years $(n=26)$. Overall, respondents estimated that a mean of $66.4 \%$ of their patients were older than 65 years.

Notably, $63 \%$ of the respondents reported none (option 1 ) to very little (option 2 ) prior education in geriatrics $(n=27)$. A total of $50 \%$ of surveyed residents reported having very little prior education $(n=6)$ and $58.8 \%$ of practicing providers reported none to very little prior education in geriatrics $(n=17)$.

When asked about levels of interest in geriatric issues as compared with issues of other age groups, $21.5 \%$ of respondents reported having little interest (options 1 and 2), 46.4\% reported having moderate interest (option 3), and $32.1 \%$ reported having high interest (options 4 or 5) in geriatric

Table 1 Survey respondents' demographic information

\begin{tabular}{|c|c|}
\hline Age $(n=21)$ & 29 to 80 y (median, 39 y) \\
\hline \multirow[t]{2}{*}{ Gender $(n=23)$} & Male: 12 \\
\hline & Female: 11 \\
\hline \multirow[t]{2}{*}{ Ethnicity $(n=23)$} & Caucasian: 20 \\
\hline & Asian: 3 \\
\hline \multirow[t]{6}{*}{ Subspecialty $(n=14)$} & General ophthalmology: 2 \\
\hline & Corneal and external disease: 5 \\
\hline & Retina: 4 \\
\hline & Neuro-ophthalmology: 1 \\
\hline & Glaucoma: 1 \\
\hline & Optometry: 1 \\
\hline \multirow[t]{6}{*}{ Level of training $(n=23)$} & Residents: 6 \\
\hline & 1 to $5 \mathrm{y}: 5$ \\
\hline & 6 to $10 \mathrm{y}: 2$ \\
\hline & 11 to $15 \mathrm{y}: 5$ \\
\hline & 16 to $20 \mathrm{y}: 1$ \\
\hline & $>20$ y: 4 \\
\hline
\end{tabular}

Note: Summary of demographic information of study respondents obtained from the third section of the study survey. issues ( $n=27$ ). A total of $66.7 \%$ of residents reported high interest in geriatrics $(n=6)$, while the majority of the practicing providers, $52.9 \%$, reported having a moderate level of interest $(n=17)$.

Of the $37 \%$ of respondents who reported having received prior education in geriatric care, some reported receiving training either through formal medical school lectures or during their geriatric, neurology, and rehabilitation medicine rotations, American Academy of Ophthalmology meeting lectures, or Masters education coursework. Others indicated receiving unique training grants or fellowships in geriatric care, receiving one-on-one mentorship with gerontologists, or working previously in hospice care where the majority of their patients were older than 65 years. Aside from attending lectures at academy meetings, none of the participants noted receiving formal training during residency.

\section{Levels of Confidence in Clinical Assessments}

Among the 22 clinical assessments in the survey, the majority of physicians had high confidence levels for 11 of the assessments (-Table 2). These assessments included identifying common causes of visual impairment in older adults, identifying associated comorbidities including delirium and depression, conducting preoperative assessments, describing the medical complications and psychological, emotional, and social challenges experienced by older adults with visual deficits, and facilitating collaborative care plans.

However, there were six clinical assessments with which the majority of participants felt considerably less confident (-Table 2). These assessments included conducting cognitive assessments of older adults, identifying polypharmacy, understanding implications of different insurance coverages for older adults, assessing social supports and living arrangements, and incorporating principles of geriatric rehabilitation.

Lastly, for the five remaining clinical assessments, the majority of survey respondents chose option 3, indicating that they had moderate confidence levels (-Table 2 ). These assessments included identifying and reducing the risks of driving accidents and falls, recognizing depression, conducting functional assessments, and understanding long-term services for older adults.

Self-reported confidence levels for the 22 clinical assessments were also compared between residents-in-training and practicing providers (-Table 3 ). Residents and practicing providers had similar confidence levels for many of the clinical assessments. However, residents felt less comfortable than providers in facilitating collaborative care, describing visionrelated quality-of-life measurements, identifying comorbidities impacting vision rehabilitation, conducting functional assessments, recognizing dementia and delirium, and incorporating principles of geriatric rehabilitation. Practicing providers, on the other hand, felt less comfortable than residents when assessing and reducing the risk for falls, accounting for cultural differences when making patient-care decisions, and understanding the role of long-term care services.

In the last 6 months, $90.9 \%$ of respondents had not made a referral to a geriatric specialist $(n=22)$, and $40.9 \%$ had not made a referral to a practitioner in another area, such as 
Table 2 Self-reported confidence levels of study respondents in performing various clinical assessments in older adults

\begin{tabular}{|c|c|c|c|}
\hline Clinical assessments & $\begin{array}{l}\text { Low confidence } \\
\text { (options } 1 \text { and 2) }\end{array}$ & $\begin{array}{l}\text { Moderate } \\
\text { confidence } \\
\text { (option 3) }\end{array}$ & $\begin{array}{l}\text { High confidence } \\
\text { (options } 4 \text { and 5) }\end{array}$ \\
\hline $\begin{array}{l}\text { Describe common causes of visual impairment in older adults } \\
(n=24)\end{array}$ & $0 \%$ & $8.3 \%$ & $91.2 \%$ \\
\hline $\begin{array}{l}\text { Describe challenges encountered by older adults with visual im- } \\
\text { pairment }(n=23)\end{array}$ & $4.3 \%$ & $8.7 \%$ & $86.9 \%$ \\
\hline $\begin{array}{l}\text { Describe medical complications of visual impairment in older adults } \\
(n=24)\end{array}$ & $4.2 \%$ & $12.5 \%$ & $83.3 \%$ \\
\hline Conduct a preoperative assessment of older patients $(n=24)$ & $4.2 \%$ & $20.8 \%$ & $75.0 \%$ \\
\hline $\begin{array}{l}\text { Describe psychological and emotional sequelae of vision impairment } \\
\text { in older adults }(n=24)\end{array}$ & $8.3 \%$ & $25.0 \%$ & $66.7 \%$ \\
\hline $\begin{array}{l}\text { Describe social and public consequences of vision impairment in } \\
\text { older adults }(n=24)\end{array}$ & $4.2 \%$ & $33.3 \%$ & $62.5 \%$ \\
\hline $\begin{array}{l}\text { Identify comorbidities that impact vision rehabilitation in the older } \\
\text { population }(n=24)\end{array}$ & $12.5 \%$ & $25.0 \%$ & $62.5 \%$ \\
\hline $\begin{array}{l}\text { Describe vision-related quality-of-life measurements in the older } \\
\text { population }(n=24)\end{array}$ & $20.8 \%$ & $25.0 \%$ & $54.2 \%$ \\
\hline Recognize delirium in older patients $(n=24)$ & $20.8 \%$ & $29.2 \%$ & $50.0 \%$ \\
\hline Recognize dementia in older patients $(n=23)$ & $17.4 \%$ & $34.8 \%$ & $47.8 \%$ \\
\hline Facilitate an interdisciplinary, collaborative team process $(n=23)$ & $30.4 \%$ & $30.4 \%$ & $39.1 \%$ \\
\hline Assess and reduce risk of driving accidents $(n=24)$ & $25.0 \%$ & $62.5 \%$ & $12.5 \%$ \\
\hline Recognize depression in older patients $(n=24)$ & $20.9 \%$ & $58.3 \%$ & $20.8 \%$ \\
\hline Assess and reduce risk for falls $(n=24)$ & $41.7 \%$ & $45.8 \%$ & $12.5 \%$ \\
\hline Conduct a functional assessment of older adults $(n=24)$ & $25.0 \%$ & $45.8 \%$ & $29.2 \%$ \\
\hline $\begin{array}{l}\text { Understand the roles of long-term care services, including home-care } \\
\text { services }(n=23)\end{array}$ & $24.8 \%$ & $39.1 \%$ & $26.0 \%$ \\
\hline $\begin{array}{l}\text { Understand implications of different insurance coverages for older } \\
\text { adults }(n=24)\end{array}$ & $75.0 \%$ & $20.8 \%$ & $4.2 \%$ \\
\hline Review medications for evidence of polypharmacy $(n=24)$ & $62.5 \%$ & $20.8 \%$ & $16.7 \%$ \\
\hline $\begin{array}{l}\text { Assess adequacy of patients' social support/living arrangements } \\
(n=24)\end{array}$ & $58.4 \%$ & $29.2 \%$ & $12.5 \%$ \\
\hline Incorporate the principles of geriatric rehabilitation $(n=24)$ & $54.2 \%$ & $33.3 \%$ & $12.5 \%$ \\
\hline $\begin{array}{l}\text { Assess for cultural differences when making decisions regarding } \\
\text { patient care }(n=24)\end{array}$ & $45.9 \%$ & $29.2 \%$ & $25.0 \%$ \\
\hline Conduct a cognitive assessment of older adults $(n=24)$ & $41.6 \%$ & $33.3 \%$ & $25.0 \%$ \\
\hline
\end{tabular}

Note: Summary of self-reported confidence levels of survey respondents. Results are stratified (bold font) based upon the predominant confidence level for each assessment (high, moderate, or low). Total number of study respondents from which percentages were calculated for each assessment is also provided.

occupational therapy, physical therapy, or social work $(n=22)$. Only $31.8 \%$ of respondents had made referrals to physicians outside their specialty over the last 2 months $(n=22)$.

\section{Discussion}

In light of the rapid rise in the older population and the comorbidities with which they present, it is more important for physicians to better understand the quality of life and health-related needs of this population. Given the high prevalence of visual impairment in this population, eye care providers need to provide tailored care toward their older patients. To achieve this, geriatric education for eye care providers is needed to ensure that the unique visual and health concerns of older adults are addressed. ${ }^{3,4,6,7}$ As such, the goal of this study was to understand perceived confidence and comfort of our eye care providers in attending to key areas of older adult care. We hypothesized that there are deficiencies in formal training and perceived confidence levels in recognizing and addressing key areas of older adult care among eye care providers. To our knowledge, this is the first study in the literature to look at self-assessments regarding geriatric care among eye care providers. 
e34 Assessing Educational Needs in Geriatric Care in Ophthalmology Venkateswaran et al.

Table 3 Comparison of self-reported confidence levels between residents-in-training and practicing providers

\begin{tabular}{|c|c|c|c|c|c|c|}
\hline \multirow[t]{2}{*}{ Clinical assessments } & \multicolumn{2}{|c|}{$\begin{array}{l}\text { Low confidence } \\
\text { (options } 1 \text { and } 2 \text { ) }\end{array}$} & \multicolumn{2}{|c|}{$\begin{array}{l}\text { Moderate confidence } \\
\text { (option 3) }\end{array}$} & \multicolumn{2}{|c|}{ High confidence (options 4 and 5) } \\
\hline & $\begin{array}{l}\text { Resident } \\
(n=6)\end{array}$ & $\begin{array}{l}\text { Practicing } \\
\text { provider } \\
(n=17)\end{array}$ & $\begin{array}{l}\text { Resident } \\
(n=6)\end{array}$ & $\begin{array}{l}\text { Practicing } \\
\text { provider } \\
(n=17)\end{array}$ & Resident $(n=6)$ & $\begin{array}{l}\text { Practicing } \\
\text { provider }(n=17)\end{array}$ \\
\hline $\begin{array}{l}\text { Describe common causes of visual } \\
\text { impairment in older adults }\end{array}$ & $0.0 \%$ & $0.0 \%$ & $16.7 \%$ & $5.9 \%$ & $83.3 \%$ & $94.1 \%$ \\
\hline $\begin{array}{l}\text { Describing challenges encountered } \\
\text { by older adults with visual } \\
\text { impairment }^{\mathrm{a}}\end{array}$ & $16.7 \%$ & $0.0 \%$ & $16.7 \%$ & $6.3 \%$ & $66.7 \%$ & $93.8 \%$ \\
\hline $\begin{array}{l}\text { Describing medical complications of } \\
\text { vision impairment in older adults }\end{array}$ & $16.7 \%$ & $0.0 \%$ & $16.7 \%$ & $5.9 \%$ & $66.7 \%$ & $88.2 \%$ \\
\hline $\begin{array}{l}\text { Describing psychological and emo- } \\
\text { tional sequelae of vision impairment } \\
\text { in older adults }\end{array}$ & $16.7 \%$ & $5.9 \%$ & $16.7 \%$ & $29.4 \%$ & $66.7 \%$ & $64.7 \%$ \\
\hline $\begin{array}{l}\text { Describing social and public conse- } \\
\text { quences of vision impairment in } \\
\text { older adults }\end{array}$ & $16.7 \%$ & $0.0 \%$ & $33.3 \%$ & $35.3 \%$ & $50.0 \%$ & $64.7 \%$ \\
\hline $\begin{array}{l}\text { Conducting a preoperative assess- } \\
\text { ment of older patients }\end{array}$ & $16.7 \%$ & $0.0 \%$ & $33.3 \%$ & $17.6 \%$ & $50.0 \%$ & $82.4 \%$ \\
\hline $\begin{array}{l}\text { Recognizing depression in older } \\
\text { patients }\end{array}$ & $16.7 \%$ & $23.5 \%$ & $83.3 \%$ & $47.1 \%$ & $0.0 \%$ & $29.4 \%$ \\
\hline $\begin{array}{l}\text { Assessing and reducing risk of driv- } \\
\text { ing accidents }\end{array}$ & $33.3 \%$ & $23.5 \%$ & $66.7 \%$ & $58.8 \%$ & $0.0 \%$ & $17.6 \%$ \\
\hline $\begin{array}{l}\text { Conducting a cognitive assessment } \\
\text { of older patients }\end{array}$ & $50.0 \%$ & $41.2 \%$ & $33.3 \%$ & $35.3 \%$ & $16.7 \%$ & $23.5 \%$ \\
\hline $\begin{array}{l}\text { Reviewing medications for evidence } \\
\text { of polypharmacy }\end{array}$ & $50.0 \%$ & $64.7 \%$ & $16.7 \%$ & $23.5 \%$ & $33.3 \%$ & $11.8 \%$ \\
\hline $\begin{array}{l}\text { Assessing the adequacy of patients' } \\
\text { social support/living arrangements }\end{array}$ & $50.0 \%$ & $58.8 \%$ & $16.7 \%$ & $35.3 \%$ & $33.3 \%$ & $5.9 \%$ \\
\hline $\begin{array}{l}\text { Understanding implications of dif- } \\
\text { ferent insurance coverages for older } \\
\text { patients }\end{array}$ & $100.0 \%$ & $70.6 \%$ & $0.0 \%$ & $23.5 \%$ & $0.0 \%$ & $5.9 \%$ \\
\hline $\begin{array}{l}\text { Facilitating an interdisciplinary, col- } \\
\text { laborative team process }{ }^{\mathrm{a}}\end{array}$ & $33.3 \%$ & $31.3 \%$ & $33.3 \%$ & $25.0 \%$ & $33.3 \%$ & $43.8 \%$ \\
\hline $\begin{array}{l}\text { Describing vision-related quality-of- } \\
\text { life measurements in the older } \\
\text { population }\end{array}$ & $50.0 \%$ & $11.8 \%$ & $33.3 \%$ & $23.5 \%$ & $16.7 \%$ & $64.7 \%$ \\
\hline $\begin{array}{l}\text { Identifying comorbidities that im- } \\
\text { pact vision rehabilitation in the older } \\
\text { population }\end{array}$ & $50.0 \%$ & $0.0 \%$ & $16.7 \%$ & $29.4 \%$ & $33.3 \%$ & $70.6 \%$ \\
\hline $\begin{array}{l}\text { Conducting a functional assessment } \\
\text { of older patients }\end{array}$ & $66.7 \%$ & $11.8 \%$ & $16.7 \%$ & $58.8 \%$ & $16.7 \%$ & $29.4 \%$ \\
\hline $\begin{array}{l}\text { Incorporating the principles of geri- } \\
\text { atric rehabilitation }\end{array}$ & $83.3 \%$ & $41.2 \%$ & $16.7 \%$ & $41.2 \%$ & $0.0 \%$ & $17.6 \%$ \\
\hline $\begin{array}{l}\text { Recognizing dementia in older } \\
\text { patients }^{\mathrm{a}}\end{array}$ & $16.7 \%$ & $18.8 \%$ & $50.0 \%$ & $31.3 \%$ & $33.3 \%$ & $50.0 \%$ \\
\hline $\begin{array}{l}\text { Recognizing delirium in older } \\
\text { patients }\end{array}$ & $16.7 \%$ & $23.5 \%$ & $50.0 \%$ & $23.5 \%$ & $33.3 \%$ & $52.9 \%$ \\
\hline Assessing and reducing risk for falls & $33.3 \%$ & $47.1 \%$ & $50.0 \%$ & $41.2 \%$ & $16.7 \%$ & $11.8 \%$ \\
\hline $\begin{array}{l}\text { Accounting for cultural differences } \\
\text { when making decisions regarding } \\
\text { patient care }\end{array}$ & $16.7 \%$ & $58.8 \%$ & $66.7 \%$ & $11.8 \%$ & $16.7 \%$ & $29.4 \%$ \\
\hline
\end{tabular}


Table 3 (Continued)

\begin{tabular}{|l|l|l|l|l|l|l|}
\hline Clinical assessments & \multicolumn{2}{l|}{$\begin{array}{l}\text { Low confidence } \\
\text { (options 1 and 2) }\end{array}$} & \multicolumn{2}{l|}{$\begin{array}{l}\text { Moderate confidence } \\
\text { (option 3) }\end{array}$} & \multicolumn{2}{l|}{ High confidence (options 4 and 5) } \\
\hline & $\begin{array}{l}\text { Resident } \\
(n=6)\end{array}$ & $\begin{array}{l}\text { Practicing } \\
\text { provider } \\
(n=17)\end{array}$ & $\begin{array}{l}\text { Resident } \\
(n=6)\end{array}$ & $\begin{array}{l}\text { Practicing } \\
\text { provider } \\
(n=17)\end{array}$ & Resident ( $n=6)$ & $\begin{array}{l}\text { Practicing } \\
\text { provider }(n=17)\end{array}$ \\
\hline $\begin{array}{l}\text { Understanding the roles of long- } \\
\text { term care services, including home } \\
\text { care services }\end{array}$ & $20.0 \%$ & $41.2 \%$ & $80.0 \%$ & $23.5 \%$ & $0.0 \%$ & $35.3 \%$ \\
\hline
\end{tabular}

Note: Comparison of self-reported confidence levels between residents-in-training and practicing providers for all clinical assessments. The predominant confidence level for each assessment is displayed in bold for both groups. Total number of study respondents from which percentages were calculated for each assessment is also provided.

anly 16 of 17 practicing providers responded to these clinical assessments.

${ }^{b}$ Only five of six residents responded to this clinical assessment.

In our study, an estimated mean of $66.4 \%$ of the patients treated by survey respondents were older than 65 years, which is consistent with 2010 Center for Disease Control data that noted that $54 \%$ of total patient visits made to ophthalmologists were by individuals older than 65 years. ${ }^{11}$ Only $37 \%$ of respondents reported having received prior education in geriatric care, but percentages were slightly higher among practicing providers (58.8\%) as compared with residents (50\%). Respondents noted that the majority of their geriatric training was provided during undergraduate medical education and continued education meetings but not during residency training. While residents and practicing providers had similar confidence levels for most clinical assessments, there were several assessments for which residents reported lower confidence levels as compared with providers. Residents did, however, report a higher interest level in geriatric issues than practicing providers. Our results suggest that residency training can be an important time during which geriatric educational programs can be implemented given identified educational needs, high interest levels, and the paucity of formal geriatric education during this time.

Many studies highlighted the difficulties physicians faced when addressing the needs of elderly patients and the lack of emphasis on geriatric issues during training, and these led to the development of the hypothesis for this study. Surveybased studies by Cantor et al and Blumenthal et al found that most physicians in various specialties who were early in their practicing careers felt that their training in medical school and residency had effectively prepared them to manage most of the common conditions they would encounter in their respective clinical practices. ${ }^{15,16}$ In our study, we found that many of our surveyed eye care providers, at varying levels of training, felt confident in diagnosing and managing common visual conditions among older patients as well as identifying the medical, emotional and psychological sequelae of these conditions. On the other hand, the studies by Cantor et al and Blumenthal et al also found that many of the physicians struggled with other aspects of patient care, such as adequately addressing the needs of nursing home or elderly patients, communicating with patients with cognitive disorders, or diagnosing depression. ${ }^{15,16}$ This was supported in our study, as $41.6 \%$ of respondents noted low confidence levels in conducting cognitive assessments of older adults, $58.4 \%$ noted low confidence in assessing the adequacy of patients' social supports and living arrangements, and only $20.8 \%$ felt highly confident in recognizing depression in their patients. A study by Drickamer et al showed that trainees (which included internal medicine residents and medical students) felt that time devoted to instruction in geriatrics was inadequate, felt uncomfortable recognizing and addressing the complex, multifactorial natures of illnesses in elderly patients, and reported feeling overwhelmed by the medical and psychosocial needs of older patients. ${ }^{17}$ Addressing the unique and complex needs of the older population is oftentimes difficult, and this was displayed in our study where surveyed providers noted moderate to low confidence levels in addressing 12 out of 22 geriatric medicine domains.

Falls are a leading cause of morbidity and mortality in the elderly. ${ }^{5,7}$ Each year, 35 to $45 \%$ of elderly individuals sustain falls, ${ }^{5}$ with approximately one-half occurring at home and one-third resulting in a fracture of the hip or thigh. ${ }^{18}$ More than $40 \%$ of these patients require hospitalization, ${ }^{5}$ and hospitalization of older adults often leads to a higher risk of subsequent functional decline. ${ }^{19}$ Several studies have shown that poor vision is an important risk factor for falls., 20 Elements such as contrast sensitivity, depth perception, stereopsis, and visual fields play critical roles in posture stabilization but can place elderly patients at risk for falls if altered secondary to ocular disease..$^{5-7,21-23}$ Hong et al showed that recent development of visual impairment in older adults was associated with an increased likelihood of subsequent falls and fractures in the next 5 years. ${ }^{18}$ In our study, $45.8 \%$ of respondents had moderate confidence levels in being able to assess and reduce the risk for falls in their older patients, but $41.7 \%$ reported low confidence levels and only $12.5 \%$ noted high confidence levels. Given the close association between visual impairment and fall risk, it is important for eye care providers to feel confident not only in identifying patients at high risk for falls, but also in offering visual rehabilitation options and facilitating referrals to practitioners in occupational therapy, physical therapy, or geriatrics who can implement additional services to mitigate fall risk. ${ }^{24}$ Training in fall-risk assessments can improve providers' knowledge base in this area and early detection of 
fall risk and timely intervention can improve patient safety and outcomes.

Vision loss impairs the ability of older adults to drive, and motor vehicle collisions increase appreciably in patients older than 70 years. ${ }^{25}$ Interestingly, standard visual acuity shows a weak relationship with older driver safety but previous studies have shown that certain types of visual impairment, such as reduced contrast sensitivity particularly in patients with cataracts, slower visual processing speeds, and visual field losses, place older adults at higher risk for motor vehicle collisions..$^{25,26}$ In 40 of the 50 states in the United States, there is a periodic vision screening for license renewal but variations in the frequency and level of testing do exist. ${ }^{5,26}$ In our study, $62.5 \%$ of study respondents noted moderate confidence levels in identifying and reducing the risks of driving accidents in older patients but only $12.5 \%$ noted high confidence levels. Eye care providers play a large role in determining whether elderly patients are safe to drive, whether it is through routine eye exams or periodic vision screening for license renewals, and there is room for improvement in being able to determine which older patients are at risk for driving accidents secondary to visual impairment.

Visual impairment can also precipitate comorbidities such as depression, delirium, and dementia in the elderly. ${ }^{5-8}$ Older patients with vision loss report poorer levels of functioning with their activities of daily living and often report symptoms of depression and anxiety. ${ }^{27}$ Vision loss is also associated with an increased risk for Alzheimer disease, ${ }^{28}$ and visual impairment can prolong hospitalization, increasing the risk for in-hospital dementia and delirium. ${ }^{5,6}$ Recognizing comorbid depression, delirium, and dementia is important when treating older patients, as health outcomes can be improved with early recognition of these conditions. In our study, nearly $50 \%$ of survey respondents noted high levels of confidence in recognizing delirium and dementia in older patients. However, only $20.8 \%$ noted high confidence levels in recognizing depression. The majority of our study respondents were not confident in their ability to assess the cognition and function of older patients. Conducting thorough and effective geriatric assessments can be difficult in older adults. However, eye care providers should be equipped with the ability to recognize relevant geriatric conditions and know when to seek assistance from primary care providers and consultants.

Many of the geriatric medicine domains for which the eye care providers in our study reported a lack of confidence can be addressed through collaborative care. A collaborative team can include a primary care provider, an eye care specialist, and practitioners in other areas such as physical therapy, occupational therapy, or nursing services. However, only $39.1 \%$ of our survey respondents reported high confidence levels in the collaborative care of older adults, and confidence levels were similar between residents and providers. In our study, $40.9 \%$ of respondents had never made a referral to a practitioner in another area, and only $31.8 \%$ of respondents had made referrals to physicians outside their specialty over the last 2 months. Working in conjunction with geriatricians and specialists in other fields can help eye care providers glean a better understanding of the effects of geriatric-specific issues such as polypharmacy, long-term care services, social supports, and geriatric rehabilitation. The skills related to working with other health care professionals, each using their areas of expertise to assess the physical and mental wellbeing of their older patients, consider the various social, environmental, and psychological factors that can exacerbate illness, and coordinate care across a variety of settings, can be targeted during residency training. This skill is invaluable to providing high-quality, geriatric-focused care. ${ }^{3}$

Given the burgeoning older adult population, the growing shortage of generalists and geriatric specialists, and the rising medical and surgical needs of older patients, there is a clear need to integrate geriatrics education and research into ophthalmology subspecialty training, yet the paramount question that remains is to how to most effectively incorporate geriatric education and training in already existing educational models. ${ }^{29}$ Education must be geared to not only residents-in-training but also practicing providers who need to expand their knowledge base and skills to be more confident in their ability to deliver better care to older adults. $^{3}$ The Accreditation Council for Graduate Medical Education (ACGME) has proposed six general core competencies that are necessary for independent clinical practice across various medical specialties, including ophthalmology. These competencies are patient care, medical knowledge, professionalism, communication and interpersonal skills, practice-based learning, and system-based practice, and their aim is to provide meaningful and continuous educational outcome assessments to improve the quality of graduate medical training. ${ }^{30,31}$ The ICO has also created a curriculum which provides educational concepts outlined in three levels of supervised ophthalmic training: basic, standard, and advanced. This curriculum aims to provide benchmarks in clinical training that can be used to assess performance and monitor progression. ${ }^{30,32}$ When creating the survey for this study, we referred to and incorporated the competencies listed under the basic, standard, and advanced levels in the low-vision rehabilitation section of the ICO curriculum, due to the high burden of visual impairment and low vision among individuals older than 65 years. ${ }^{33}$

Sets of geriatric competencies have been published by the American Geriatrics Society for many fields ,including internal medicine, family medicine, emergency medicine, psychiatry, surgery, nursing, and pharmacy in efforts to enhance understanding of geriatric care across specialties and optimize patient care. ${ }^{34}$ Given the emphasis on competencybased education for resident training, we believe that to incorporate geriatric education into the existing ACGME curricula in the United States, educators will need to design new teaching tools that can be directly implemented into each of the six core competencies. Creation of new educational programs will reinforce specific learning objectives and curricula in the elements of geriatric care that are important for eye care providers and will permit standardization of training experiences. ${ }^{4}$ Through continuous ACGME-based assessments, areas in need of improvement can be constantly identified and addressed. Developing research agendas in geriatric care to increase expertise, as done by Friedman and 
Lee, and encouraging gerontological research among training physicians can also be pursued to promote geriatric ophthalmology. ${ }^{4-7}$ Ultimately, future studies can be conducted to evaluate the effectiveness of education and training in improving the confidence of eye care providers in employing geriatric medicine principles when caring for older adults.

Several geriatric training initiatives have been reported in the literature and have been shown to be successful in changing the course of geriatrics education for trainees with varying levels of experience. Reuben et al conducted an analysis on geriatric training programs implemented at 10 institutions and found that the newly created educational materials, rotations, coursework, and faculty development programs had resulted in the training of more than 1,000 medical students, 500 residents, 100 faculty, and 700 nonfaculty community physicians and had provided geriatrics/gerontology training across 22 non-primary care disciplines, including ophthalmology. ${ }^{35}$ Christmas et al described the creation of a "Geriatrics Mini-Fellowship," a 3-day interactive course that reviewed medical topics relevant to older adults. Self-rated knowledge about geriatric syndromes, self-rated efficacy to teach geriatrics, and reported value for learning about geriatrics all improved after this course among participants, which included 42 nongeriatrician clinician-educator faculty. ${ }^{36}$ The Geriatrics Education for Specialty Residents program has also helped pilot methods to incorporate geriatrics within residency programs, including ophthalmology residencies, develop new curricular content, and develop faculty leaders in geriatrics. Initiatives have included development of new web-based and point-of-care educational tools on geriatric-specific issues as well as organization of interactive teaching activities (bedside rounds, home visits) lecture series, grand rounds, journal clubs, and multidisciplinary conferences between specialists and geriatricians. ${ }^{29}$ These programs have certainly made strides in improving geriatric education but have also been met with challenges, including limited available time to add geriatric content to existing curricula and time constraints of faculty members to teach trainees and pursue research in geriatric education. Over time, educational programs of varying structures can be integrated into academic ophthalmology curricula to engage physicians in continued training in the care of older adults and increase the number of health care professionals who employ principles of geriatric medicine when caring for older adults. ${ }^{29,30,34,35}$

Our study provides valuable insights on extent of training and perceived competency in geriatric care in ophthalmology. It sheds light on differing confidence levels among providers in caring for older adults. However, this study also has several limitations that reduce the generalizability of results. First, our study was limited to one academic center and had a small sample size. The total number of respondents per question also varied and questions not answered on respondents' surveys were not included in the final data analysis, further decreasing the sample size. Second, the results were based on self-report, rather than objective measurements of practice patterns, and it is possible that self-perceived confidence levels have little correlation with actual competency in many of these domains. In future studies, distribution of surveys to multiple institutions can augment the sample size and enable researchers to obtain more data and analyze trends across institutions. Objective measures of clinical practice patterns in ophthalmology can be added to the survey to generate further recommendations for improvement in geriatric education and training in ophthalmology.

Friedman et al conducted a survey-based study to determine differences in confidence levels, knowledge, and selfreported practice behaviors between geriatricians and hospitalists in caring for hospitalized older adults. Areas of significant difference were identified, and they proposed platforms for potential faculty development programs that could address gaps in knowledge, improve older patient care, and ultimately "geriatricize hospitalists." ${ }^{\text {14 }}$ The concept of "geriatricizing" can certainly be extended to the ophthalmology community, given the need for increased sensitivity and awareness to issues affecting aging patients with visual impairment. Through this study, we have identified several areas of geriatric medicine associated with lower confidence levels that can serve as a framework to guide future educational programming and infrastructure targeted toward "geriatricizing" ophthalmologists and improving the quality of subspecialty ophthalmologic care provided to the rapidly growing older adult population.

\section{Conflict of Interest}

None

\section{Financial Support}

This study was supported by Donald W. Reynolds

Foundation Subspecialty Grant.

\section{Acknowledgment}

The authors would like to thank Christine Callan for her assistance in creating and distributing our electronic survey as well as creating an electronic database in which survey answers were stored.

\section{References}

1 Werner CA. U.S. Bureau of the Census 2010 Census Briefs. The older population: 2010. November 2011. Available at: http:// www.census.gov/prod/cen2010/briefs/c2010br-09.pdf

2 Day JC. U.S. Bureau of the Census, Current Population Reports P251130. Population Projections of the United States by Age, Sex, Race and Hispanic Origin: 1995 to 2050. Washington, DC: U.S. Government Printing Office; 1996. Available at: http://www.census.gov/ prod/1/pop/p25-1130.pdf

3 O'Neill G, Barry PP. Training physicians in geriatric care: responding to critical need. Public Policy and Aging Report 2000; 13:17-21

4 Lee AG, Liesegang T. Increasing geriatrics expertise in ophthalmology. Ophthalmology 2002;109(4):635-636

5 Centers for Disease Control. National Ambulatory Medical Care Survey Factsheet: Ophthalmology. Available at: http://www.cdc. gov/nchs/data/ahcd/NAMCS_2010_factsheet_ophthalmology.pdf

6 Lee AG, Coleman AL. Research agenda-setting program for geriatric ophthalmology. J Am Geriatr Soc 2004;52(3):453-458 
7 Friedman DS, Lee A. Geriatric ophthalmology. In: LoCicero J III, Rosenthal RA, Katlic MR, Pompei P eds. A Supplement to New Frontiers in Geriatrics Research: An Agenda for Surgical and Related Medical Specialties. New York, NY: American Geriatrics Society; 2007:161-180

8 Lee AG, Beaver HA. Geriatric ophthalmology. In: Rosenthal RA, Zenilman ME, Katlic MR eds. Principles and Practice of Geriatric Surgery. New York, NY: Springer-Verlag; 2011:513-523

9 Rosenthal BP. Ophthalmology. Screening and treatment of agerelated and pathologic vision changes. Geriatrics 2001;56(12): 27-31, quiz 32

10 National Eye Institute. Statistics and Data. Available at: https:// www.nei.nih.gov/eyedata

11 Congdon N, O'Colmain B, Klaver CC, et al; Eye Diseases Prevalence Research Group. Causes and prevalence of visual impairment among adults in the United States. Arch Ophthalmol 2004; 122(4):477-485

12 Massof RW. A model of the prevalence and incidence of low vision and blindness among adults in the U.S. Optom Vis Sci 2002;79(1): 31-38

13 International Council of Ophthalmology. International Council of Ophthalmology Residency Curriculum, Low Vision Rehabilitation. 2012. Available at: http://www.icoph.org/dynamic/attachments/ curriculum_documents/pdf_doc/updated-ico-residency-curriculum.pdf

14 Friedman SM, Gillespie SM, Medina-Walpole AM, CaprioTV, Karuza J, McCann RM. "Geriatricizing” hospitalists: identifying educational opportunities. Gerontol Geriatr Educ 2013;34(4):409-420

15 Cantor JC, Baker LC, Hughes RG. Preparedness for practice. Young physicians' views of their professional education. JAMA 1993; 270(9):1035-1040

16 Blumenthal D, Gokhale M, Campbell EG, Weissman JS. Preparedness for clinical practice: reports of graduating residents at academic health centers. JAMA 2001;286(9):1027-1034

17 Drickamer MA, Levy B, Irwin KS, Rohrbaugh RM. Perceived needs for geriatric education by medical students, internal medicine residents and faculty. J Gen Intern Med 2006;21(12):1230-1234

18 Hong T, Mitchell P, Burlutsky G, Samarawickrama C, Wang JJ. Visual impairment and the incidence of falls and fractures among older people: longitudinal findings from the Blue Mountains Eye Study. Invest Ophthalmol Vis Sci 2014;55(11):7589-7593

19 Covinsky KE, Palmer RM, Fortinsky RH, et al. Loss of independence in activities of daily living in older adults hospitalized with medical illnesses: increased vulnerability with age. J Am Geriatr Soc 2003;51(4):451-458

20 Klein R, Klein BE, Linton KL, De Mets DL. The beaver eye dam study: visual acuity. Ophthalmology 1991;98(8):1310-1315

21 Lord SR, Menz HB. Visual contributions to postural stability in older adults. Gerontology 2000;46(6):306-310

22 Lord SR, Dayhew J. Visual risk factors for falls in older people. J Am Geriatr Soc 2001;49(5):508-515
23 Ambrose AF, Paul G, Hausdorff JM. Risk factors for falls among older adults: a review of the literature. Maturitas 2013;75(1): 51-61

24 Campbell AJ, Robertson MC, La Grow SJ, et al. Randomised controlled trial of prevention of falls in people aged $>$ or $=75$ with severe visual impairment: the VIP trial. BMJ 2005;331(7520): 817

25 Sandlin D, McGwin G Jr, Owsley C. Association between vision impairment and driving exposure in older adults aged 70 years and over: a population-based examination. Acta Ophthalmol (Copenh) 2014;92(3):e207-e212

26 Huisingh C, McGwin G Jr, Wood J, Owsley C. The driving visual field and a history of motor vehicle collision involvement in older drivers: a population-based examination. Invest Ophthalmol Vis Sci 2015;56(1):132-138

27 Kempen GI, Ballemans J, Ranchor AV, van Rens GH, Zijlstra GA. The impact of low vision on activities of daily living, symptoms of depression, feelings of anxiety and social support in communityliving older adults seeking vision rehabilitation services. Qual Life Res 2012;21(8):1405-1411

28 Uhlmann RF, Larson EB, Koepsell TD, Rees TS, Duckert LG. Visual impairment and cognitive dysfunction in Alzheimer's disease. J Gen Intern Med 1991;6(2):126-132

29 Potter JF, Burton JR, Drach GW, Eisner J, Lundebjerg NE, Solomon DH. Geriatrics for residents in the surgical and medical specialties: implementation of curricula and training experiences. J Am Geriatr Soc 2005;53(3):511-515

30 Lee AG, Chen Y. Structured curricula and curriculum development in ophthalmology residency. Middle East Afr J Ophthalmol 2014; 21(2):103-108

31 Lee AG, Arnold AC. The AGCME milestone project in ophthalmology. Surv Ophthalmol 2013;58(4):359-369

32 Tso MO, Goldberg MF, Lee AG, Selvarajah S, Parrish RK II, Zagorski Z. An international strategic plan to preserve and restore vision: four curricula of ophthalmic education. Am J Ophthalmol 2007; 143(5):859-865

33 Scott IU, Smiddy WE, Schiffman J, Feuer WJ, Pappas CJ. Quality of life of low-vision patients and the impact of low-vision services. Am J Ophthalmol 1999;128(1):54-62

34 The American Geriatrics Society. Existing Formal Geriatrics Competencies and Milestones. Available at: http://www.americangeriatrics.org/health_care_professionals/education/curriculum_guidelines_competencies/ existing_formal_geriatrics_competencies

35 Reuben DB, Bachrach PS, McCreath $\mathrm{H}$, et al. Changing the course of geriatrics education: an evaluation of the first cohort of Reynolds geriatrics education programs. Acad Med 2009; 84(5):619-626

36 Christmas C, Park E, Schmaltz H, Gozu A, Durso SC. A model intensive course in geriatric teaching for non-geriatrician educators. J Gen Intern Med 2008;23(7):1048-1052 